\section{(C) OPEN ACCESS}

\title{
Tracking and tracing the tobacco industry: potential tobacco industry influence over the EU's system for tobacco traceability and security features
}

\author{
Allen William Andrew Gallagher, ${ }^{0}$ Anna B Gilmore, ${ }^{1}$ Michael Eads ${ }^{2}$
}

- Additional material is published online only. To view please visit the journal online (http://dx.doi.org/10.1136/ tobaccocontrol-2019-055094).

${ }^{1}$ Tobacco Control Research Group, Department for Health, University of Bath, Bath, UK ${ }^{2}$ Sovereign Border Solutions, Cape Town, South Africa

\section{Correspondence to} Allen William Andrew Gallagher, Health, University of Bath Department for Health, Bath BA2 7AY, UK;

a.a.gallagher@bath.ac.uk

Received 4 April 2019 Revised 7 July 2019

Accepted 9 July 2019
D Check for updates

(C) Author(s) (or their employer(s)) 2019. Re-use permitted under CC BY-NC. No commercial re-use. See rights and permissions. Published by BMJ.

To cite: Gallagher AWA, Gilmore $A B$, Eads $M$. Tob Control Epub ahead of print: [please include Day Month Year]. doi:10.1136/ tobaccocontrol-2019-055094

\section{ABSTRACT}

Background Subsequent to the transnational tobacco companies' (TTC) history of involvement in tobacco smuggling, the Illicit Trade Protocol (ITP) requires that tobacco tracking and tracing (T\&T) systems be established independent of the industry. In response, TTCs developed a T\&T system, originally called Codentify, promoting it via an elaborate set of front groups to create a false impression of independence. The European Union (EU) is one of the first and largest jurisdictions to operationalise T\&T. We explore how industry efforts to influence T\&T have evolved.

Methods Analysis of tobacco industry documents, policy documents, submissions to a relevant consultation and relationships between the tobacco industry and organisations proposed by it and approved by the European Commission to provide a data repository function within the EU's T\&T system.

Findings 17 months after TTCs sold Codentify to Inexto and Philip Morris International claimed Inexto was independent, leaked documents suggest TTCs and Inexto continued to have a financial and operational relationship. Inexto's meetings with TTCS, engagement with EU Member States and promotion of industryfavoured technical standards suggest TTCs influenced Inexto's activities, using the company to undermine EU T\&T. The EU's T\&T system appears to be inconsistent with the ITP due to its 'mixed' governance and seven of eight organisations approved as data repository providers having pre-existing industry business links.

Conclusions TTC's efforts to maximise their control and minimise external scrutiny of T\&T systems seriously limit attempts to address tobacco smuggling. Countries implementing T\&T should be alert to such efforts and should not replicate the EU system.

\section{INTRODUCTION}

Article 15 of the WHO Framework Convention on Tobacco Control (FCTC) and its supplementary treaty, the Protocol to Eliminate Illicit Trade in Tobacco Products/the Illicit Trade Protocol (ITP), aim to enable a co-ordinated international response to the illicit tobacco trade. The ITP came into force in September 2018 and, as of March 2019, has 51 Parties, including the European Union (EU). ITP Article 8 sets a deadline of 25 September 2023 for a global cigarette tracking and tracing (T\&T) system to be established by each Party to the Protocol, with an additional 5 years being given for any additional products containing leaf tobacco. ${ }^{1}$

$\mathrm{T} \& \mathrm{~T}$ is a means of supply chain control and its use in this field is fundamentally a response to overwhelming evidence of tobacco company involvement in illicit trade (including complicity in tobacco smuggling). ${ }^{2-11}$ In line with this and the FCTC's acknowledgement of the 'irreconcilable conflict' between the tobacco industry and public health, the ITP requires that Parties must not delegate their T\&T obligations to the industry and should be in contact with the industry and its representatives 'only to the extent strictly necessary' to implement Article 8 (on T\&T) requirements. ${ }^{1}$

Despite tobacco industry claims of utilising robust supply chain security systems, ${ }^{12}$ evidence indicates that tobacco companies continue to fail to control their supply chains. ${ }^{11}$ As such, a strong T\&T system could lead to them having to make increased tax payments and, were it to demonstrate involvement in tobacco smuggling or a failure to address it, to further litigation. The industry therefore has a vested interest in controlling these systems. ${ }^{11}$ In line with this, Transnational Tobacco Companies (TTCs)—namely Philip Morris International (PMI), British American Tobacco (BAT), Japan Tobacco International (JTI) and Imperial Tobacco (now Imperial Brands) (IB), have tried to undermine the ITP's intention to develop an effective global T\&T system by creating and promoting their own inadequate $^{13}$ and inefficient ${ }^{14}$ system, first known as Codentify. ${ }^{15}$

Despite PMI's claim that it is 'not in the track and trace business', in the mid-2000s PMI patented Codentify and in 2010 licensed it for free to BAT, JTI and IB. The four tobacco companies then worked collectively to promote Codentify's adoption. ${ }^{1116}$ A key part of this strategy has been to use third-parties to create the false impression that Codentify is independent from the tobacco industry and thus compliant with the ITP. One of these third parties was the Digital Coding and Tracking Association (DCTA) which was registered by all four TTCs in 2011 and promoted Codentify, often without disclosing its own relationship to the tobacco industry. ${ }^{13} 1718$ The industry's third party strategies have since become more elaborate and include the 2016 sale of Codentify to the technology company Inexto.

JTI's Vice-President of illicit trade prevention has claimed that the transfer occurred because 'a specialised technology company is better placed to further develop the technology,12 and Inexto's Managing Director stated that PMI sold the system because it was not its 'core business'. ${ }^{19}$ However, several of Inexto's top officials are former PMI employees and co-creators of Codentify (including the Managing Director). ${ }^{11} 2021$ 
The industry's promotion of its own T\&T system has been part of a broader effort by tobacco companies to reshape their history of involvement in tobacco smuggling and ingratiate themselves with governments as partners in reducing illicit trade. $^{611} 13$ Examples include tobacco companies engaging in voluntary partnerships or Memorandums of Understanding with law enforcement and custom agencies, ${ }^{22}$ funding enforcement agencies, such as Interpol, ${ }^{13}$ sniffer dogs for illicit tobacco raids $^{23}$ and illicit trade research globally, ${ }^{24-27}$ hiring former law enforcement officials ${ }^{28}$ and training border patrol and customs officials. ${ }^{6}$ It is within this context of growing recent evidence of both tobacco industry involvement in illicit trade and attempts to undermine the ITP that the EU and its Member States began operationalising the ITP's requirements.

This occurred in two phases-the legislative phase in which the legislative requirements for T\&T were included in the Tobacco Products Directive (TPD), ${ }^{11}$ adopted on 3 April $2014,{ }^{29}$ and then the implementation phase which led to the adoption of delegated and implementing regulations in December 2017..$^{30} 31$ On 20 May 2019, T\&T for cigarettes and roll-your-own tobacco was implemented in the EU, based on these regulations. ${ }^{32}$

Concerns were raised that the final wording of the TPD in relation to T\&T gave tobacco manufacturers considerable influence over key elements of the system. ${ }^{33}$ The TPD specifies that tobacco manufacturers (rather than Member States) 'should conclude data storage contracts with independent third parties'. ${ }^{11}$ These contracts are for the creation and operation of data repositories which store traceability data for each country crucial to the T\&T process. The text also specifies that external auditors required to monitor these third parties should be 'proposed and paid by the tobacco manufacturer', although 'approved' by the Commission. ${ }^{29}$ Auditors conduct announced or unannounced audits on, and produce annual reports about the integrity of, the repository they are contracted to audit.

The implementation phase was led by the European Commission which undertook a range of assessments, analyses and consultations ${ }^{303134-42}$ culminating in the production of the final implementing and delegated regulations. ${ }^{3031}$ These specified the rules that EU Member States must abide by as they implement T\&T including, inter alia (online supplementary appendix 1), the criteria for the data repositories and auditors mentioned in the original legislation. The regulations also outlined roles for both primary (national) data repositories and a single European-wide secondary repository containing a copy of all data stored in every primary repository. ${ }^{31}$

As a result of the original legislative text (the TPD), which noted that tobacco manufacturers should agree data storage contracts with 'independent' third-parties, tobacco companies suggested third-parties to the Commission. The Commission then released a list of those deemed suitable for operating data repositories, ${ }^{35}$ using three independence criteria (box 1). Neither the original list of third-parties put forward by tobacco companies to the Commission nor the list of auditors selected by tobacco companies and approved by the Commission are currently known.

Concerns have now been raised that the delegated and implementing regulations ${ }^{43} 44$ 44-46 allow a degree of industry influence incompatible with the ITP and the International Tax Stamp Association (ITSA) has filed a case against the European Commission. ITSA's claim is that the regulations breach the ITP because the EU T\&T system is not under the exclusive control of the Commission or Member States. ${ }^{46} 47$

This study therefore aims to explore whether and how the tobacco industry has attempted to influence EU T\&T
Box 1 The European Commission's Independence Criteria for Tobacco Tracking and Tracing Across the European Union

The European Commission uses three criteria to establish the independence of a third-party, including unique identifier (non-removable identification markings which are affixed to or form part of unit packs) issuers and data repository providers, involved in the T\&T system from the tobacco industry:

- Legal, organisational and decision-making independence.

- Financial independence (that less than $10 \%$ of a thirdparty's annual worldwide turnover comes 'from goods and services supplied to the tobacco sector over the past two calendar years'. ${ }^{31}$ The threshold then becomes $20 \%$ for each subsequent year. ${ }^{30}$ No explanation is provided as to why these particular thresholds were chosen.

- Absence of conflicts of interests, namely that directors and other governing individuals have not participated in tobacco industry company structures in the last 5 years and shall act independently from any financial or other links to the tobacco industry such as tobacco stocks or private pension programmes. $^{30}$

implementation, whether data repository providers in the EU's T\&T system are independent and if the system is compliant with Article 8 of the ITP. It is the first study to critically explore T\&T implementation. Given that the EU's T\&T system is both one of the first and the largest implementations of tobacco $T \& T$ and its solution paradigm is therefore likely to be adopted by other Parties to the ITP, this study's findings have global relevance.

\section{METHODOLOGY}

To understand tobacco company efforts to influence EU T\&T implementation and ongoing links between the tobacco industry and Inexto, this paper follows on from previous research ${ }^{11}$ by analysing two additional leaked industry documents, ${ }^{48} 49$ dated October-November 2017. Qualitative thematic analysis, based on a hermeneutic approach to company document analysis, ${ }^{50}$ was applied with analysis focussing specifically on influence within the EU. Attempts were made to triangulate findings via data from other sources namely online news media and academic journals. Findings from this analysis led us to also analyse responses to the Commission's targeted stakeholder consultation $^{51}$ (held in May 2015 as part of the implementation phase) to determine which respondees endorsed a specific proposal mentioned in the documents.

To identify relationships between the tobacco industry and data repository providers approved by the European Commission as 'independent', the business relationships between these providers and PMI, BAT, JTI, and IB were systematically assessed. We used a process developed from existing approaches, ${ }^{52}$ involving searches of corporate monitoring databases (Tobacco Tactics, Sourcewatch, Powerbase and Spinwatch), industry documents (Legacy Library) and other resources (actor and tobacco company websites, Google search results and the EU Transparency register).

To determine the EU T\&T system's compliance with Article 8 of the ITP, the implementing and delegated acts relating to T\&T adopted by the European Commission in December $2017^{30} 31$ were compared with the requirements of Article 8 of the ITP. ${ }^{53}$ NVivo was used to code the specific requirements of Parties within Article 8's 14 obligations and to identify where these are 
met, and potential inconsistencies, within the implementing and delegated acts. Further, a range of EU policy documents (T\&T feasibility study, implementation analysis, summaries of the stakeholder and public consultations on T\&T and the draft secondary legislation) $)^{303134-42}$ were reviewed to provide contextual insight into the policy process leading to the final regulations.

\section{RESULTS}

\section{Tobacco companies' ongoing relationship with Inexto and engagement with EU Member States}

Analysis of the two industry documents ${ }^{48} 49$ suggests that financial independence between PMI and Inexto had yet to be established 17 months after the 1 June 2016 sale of Codentify ${ }^{20}$ to Inexto, despite PMI's claim that 'Inexto is fully independent from the tobacco industry ${ }^{21}$ and Inexto's Managing Director's claim that 'we are independent'. ${ }^{19}$

Minutes from two meetings, dated 2 October 2017 and 7 November 2017, ${ }^{48} 49$ show that senior management from PMI, JTI, BAT, IB and representatives of Inexto, including the CEO, met monthly under an 'Operational Management Committee'. ${ }^{48} 49$ The minutes refer to a 'Spinoff 2.0' where the relationship between the tobacco industry front group, ${ }^{54}$ the DCTA (made up of representatives from BAT, PMI, IB and JTI), ${ }^{17} 18$ and Inexto is discussed. The October meeting minutes outline that a 'more arms-length services arrangement' was being worked towards but that 'Further clarity is needed on how revenue independence will be achieved on the Inexto/ Impala side ${ }^{49}$ (Impala being Inexto's parent company). ${ }^{55}$ It is unclear whether this was ever reached. This discussion took place less than a month after the Commission's draft independence criteria, which featured revenue requirements, had been published. $^{36}$

The minutes also show that, despite financial independence between Inexto and the tobacco industry seemingly not yet having been established, a series of meetings between Inexto and EU Member State government divisions occurred. The minutes refer to a meeting between Inexto and a 'national security printer' in the Czech Republic, a planned meeting between Inexto, Logista (a distributor of tobacco products in Southern Europe, of which IB holds a majority share $)^{56}$ and Spain's Royal Mint and a pilot project between Inexto and Poland's national security printer. ${ }^{49}$ These follow on from a 2016 T\&T pilot project by the German Print Office of which BAT and PMI were partner companies. ${ }^{57}$

\section{Failed tobacco industry and Inexto effort to influence EU T\&T implementation}

Unique identifiers, required on cigarette packs by the ITP, are non-removable identification markings which are affixed to or form part of unit packs ${ }^{53}$ and under the EU system take the form of alphanumeric codes. ${ }^{35}$ The November meeting minutes note that 'Inexto worked out a sGTIN (sic) proposal for the TPD Unique Identifier'. ${ }^{48}$ SGTIN (Serialised Global Trade Item Number) is an identifier for trade items developed by GS1, which designs and implements supply and demand chain solutions. SGTIN therefore falls under GS1 standards in which brand owners (who, in the case of tobacco products, are usually the manufacturers) are responsible for the generation of unique identifiers. ${ }^{58-60}$ In 2014 , the DCTA commissioned GS1 and KPMG (which has a longstanding history of being commissioned by the tobacco industry to conduct research and produce reports on illicit trade) ${ }^{61-64}$ to produce a report on T\&T which highlights GS1 standards. ${ }^{65}$

In their responses to the Commission's targeted stakeholder consultation (held from May-July 2015), ${ }^{51}$ BAT, PMI, IB and
JTI all stated that GS1 was their preferred standardisation body for the generation of unique identifiers, with PMI, IB and JTI, as well as the DCTA, endorsing SGTIN specifically ${ }^{66-70}$ (online supplementary appendix 2 is a complete list of respondees who endorsed SGTIN).

In November 2017, the European Commission stated that any reference to GS1 standards in the EU's T\&T regulations would not be 'legally acceptable' as allowing for self-generation of unique identifiers would not ensure the T\&T system's full independence from the tobacco industry. ${ }^{71}$ This intervention prevented the industry's SGTIN proposal from going on to become part of the EU's T\&T system with the task of applying unique identifiers instead going to an 'independent' thirdparty appointed by each Member State (online supplementary appendix 1). Independence of the parties is determined using the European Commission's criteria (box 1)..$^{303134}$

\section{Independence of data repository providers}

In line with the TPD text, the tobacco industry supplied names of potential data repository providers from which the European Commission, based on its independence criteria (box 1), identified eight as independent and therefore suitable. Eight were identified as primary data repository providers (Atos AG, Atos Information Technology GmbH, Atos IT Solutions and Services A/S, Atos Polska S.A, Dentsu Aegis Network Switzerland AG, IBM, Movilizer and Zetes) and one of the same companies (Dentsu Aegis Network Switzerland AG) as the secondary provider. However, our analysis shows that seven of the eight (all other than Zetes) have prior business links with TTCs, with four being subsidiaries of a single company, Atos.

Atos subsidiaries (Atos AG, Atos Information Technology GmbH, Atos IT Solutions and Services A/S, Atos Polska S.A.)

As outlined in previous research, ${ }^{11}$ Atos has extensive business links to the tobacco industry. Atos was involved in the development of Codentify and a 2012 BAT email named Atos as approved, by the TTC, to represent Codentify globally. Atos promoted Codentify in Asia and was involved in its implementation in Lithuania alongside the DCTA. ${ }^{11}$ Atos is also a member of The Coalition Against Illicit Trade, ${ }^{72}$ whose submissions to both the EU T\&T stakeholder consultation and EU transparency register failed to mention that six of the, then seven, members had business links to the tobacco industry. ${ }^{11}$

\section{IBM UK limited}

In 2013, IBM contributed to PMI's sbv IMPROVER funding initiative which awarded grants to scientists who put forward research proposals under defined themes set by PMI. ${ }^{73}$ The sbv IMPROVER initiative has been criticised for attempting to muddy the waters on the causal link between tobacco and disease, with PMI using its partnership with IBM to attempt to gain legitimacy among the scientific community. ${ }^{74}$ The sbv IMPROVER website now states that IBM Research is no longer working on the project. $^{75} \mathrm{Sbv}$ IMPROVER resembles another PMI funding initiative-PMI IMPACT, which adopts a similar approach, funding a range of projects related to ITT. ${ }^{26} 2776$ IBM also developed its own T\&T system, CLEAR, which was advertised as an ITP-compliant technology which tobacco companies could employ. ${ }^{77}$

\section{Dentsu Aegis network Switzerland AG}

Dentsu Aegis Network Switzerland AG is a subsidiary of Dentsu which had PMI as a client in the mid-1990s and early 
2000s. ${ }^{78} 79$ The Dentsu Aegis Network purchased blue-infinity in $2017^{80} 81$ - a digital technology company which, since at least 2013, has been closely involved with Codentify and the tobacco industry. Its website claims that it has 'integrated Codentify solutions for all major players in the tobacco industry,. ${ }^{82}$ It also states that blue-infinity is a 'technology partner' of $\mathrm{JTI}^{83}$ and built an 'e-commerce solution' for PMI. ${ }^{84}$

Blue-infinity's T\&T system 'AIT Central' (which features Codentify) has been promoted by blue-infinity and Videojet (a printing and marking company which advertises Codentify-compatible printing services ${ }^{85}$ as a suitable system for compliance with the TPD).$^{82}$ Blue-Infinity also cohosted a workshop for manufacturers on their T\&T technology and TPD requirements. ${ }^{82}$

\section{Movilizer $\mathrm{GmbH}$}

In 2010, Movilizer created and developed a Codentify-compatible information system for $\mathrm{BAT}^{86}$ with BAT then rolling out Movilizer in 42 countries. ${ }^{8788}$ A Movilizer partner website states that BAT and IB use Movilizer to manage and process T\&T data in locations across Europe. ${ }^{89}$

\section{Zetes S.A.}

No prior business relationships were identified.

\section{Compliance with ITP}

Our comparison of EU policy documents with the requirements of Article 8 of the ITP suggests that the EU's T\&T system may not meet all obligations specified in Article 8, namely those which refer to the control of a T\&T system and how tasks within the system are delegated. The key underlying elements of the EU's T\&T system responsible for these potential breaches are outlined below.

\section{The responsibilities of the tobacco industry}

In line with the TPD text, the EU's T\&T system allows tobacco companies to select data repository providers and to select auditors who will monitor the behaviour of these parties (both after approval from the European Commission). By allowing tobacco companies to select and pay actors crucial to both the implementation and control of the EU system, the EU T\&T regulations may be inconsistent with ITP Article 8.2's requirement that the T\&T system should be 'controlled by the Party'. 1

\section{The EU system's 'mixed' governance structure}

The EU's T\&T system takes a 'mixed' governance approach which hands further control of the system to tobacco companies. As part of the implementation phase, the European Commission commissioned an implementation analysis in $2015^{40}$ and in 2016 undertook an impact assessment on T\&T. ${ }^{38}$ Both explored three options for the governance of the EU's T\&T system: a system operated exclusively by industry, a mixed solution governed by 'industry and third party', ${ }^{38}$ and a third-party system (with tobacco companies still choosing and paying data repository providers and auditors). The implementation analysis recommended that a 'mixed solution' governed by industry and third-parties would be optimal. ${ }^{40}$

The approach reflected in the EU's T\&T system aligns with this, allowing tobacco manufacturers to assign responsibility for the installation of anti-tampering devices and the generation and application of security features. Tobacco companies thus have primary and fiduciary relationships with service providers rather than these being between service providers and governments directly.
This suggests that the EU's T\&T system is not compliant with both Article 8.2 of the ITP which states that each Party shall establish a T\&T system 'controlled by the Party' and Article 8.12 which states that 'Obligations assigned to a Party shall not be performed by or delegated to the tobacco industry'. ${ }^{33}$ This concern is furthered by the lack of safeguards within the system to protect against potential industry influence as the third-party solution outlined in the implementation analysis would have involved additional control mechanisms which the mixed solution lacks. ${ }^{37}$

\section{DISCUSSION \\ Key findings}

The findings from this paper demonstrate that the tobacco industry has made concerted efforts to influence implementation of T\&T in the EU and has been largely successful in maximising industry control and minimising independence of EU T\&T. To secure this influence, TTCs operated collectively and with a supposedly independent third-party (Inexto) at both Member State and EU level. Inexto engaged with Member State authorities and developed a policy proposal based on GS1 standards (SGTIN) which, if approved by the European Commission, would have handed additional EU T\&T responsibilities to the industry.

Our findings show that the industry's strategic use of, or interaction with, third parties seemingly in order to secure control of T\& $\mathrm{T}^{11}$ has continued both through Inexto and by the industry selecting companies with which it has close business links to be providers of key elements (eg, data repositories) of EU T\&T.

Key to the tobacco industry's strategy to undermine EU T\&T was its ongoing relationship with Inexto which documents suggest $\mathrm{PMI}^{21}$ and Inexto ${ }^{19}$ publicly misrepresented. Meeting minutes analysed in this paper raise doubt over whether Inexto's independence from the industry was ever a serious prospect. The focus on revenue independence in the minutes was likely a response to the European Commission's financial requirements for independence (box 1) and suggests that the industry and Inexto were working together to meet criteria which this paper argues are inadequate. It remains unclear whether independence between Inexto and the industry has now been established.

Indeed, rather than operating independently, evidence from the monthly meetings between Inexto and TTCs suggest that they may have been working together to maximise industry control of EU T\&T. The meetings and pilot projects between Inexto and EU Member State authorities could be viewed as attempts to influence EU Member States in favour of industry-preferred T\&T approaches. Links with national printing offices can be useful for tobacco companies as many of these offices have been designated to generate unique identifiers as part of the EU T\&T system.

The jointly developed plan to promote GS1 standards would have given further control to the industry by allowing them to generate unique identifiers. The intervention from the European Commission which rejected this proposal demonstrates the Commission's efforts to protect the EU T\&T's system integrity. While the Commission's ability to do this was limited by the underpinning legislative text, other shortfalls in implementation occurred which raise serious concerns over the EU T\&T system's compliance with the ITP.

These include the 'mixed' approach to governance selected by the Commission and its independence criteria for vetting third-parties (box 1). Our finding that seven of the eight organisations identified by the Commission as meeting the independence criteria have prior business links with the tobacco industry demonstrates that these criteria are inadequate for ensuring the 
systems' independence from the industry. While it is currently unknown which auditors have been selected, there are likely to be questions as to whether they are wholly independent from the industry given its previous work with the world's major accountancy firms (with Ernst \& Young, ${ }^{90}$ Deloitte, ${ }^{91} \mathrm{KPMG}^{64}$ and $\mathrm{PwC})^{92}$ all having been commissioned by the industry to produce reports on illicit tobacco, many of which have been criticised for inaccuracy. ${ }^{24}$

\section{Strengths and limitations}

This research is limited to data that are publicly available and documents provided to us. Our work only examines tobacco industry influence on the implementation phase (post-TPD), though problems seem to have arisen in the legislative phase also. The industry significantly influenced the TPD ${ }^{9394}$ and while previous analyses did not extend to T\&T provisions, influence on those provisions also seems likely.

Our findings are consistent with concerns raised in previous research on tobacco industry attempts to influence $T \& \mathrm{~T}^{11}$ and the difficulties of policing Article 5.3 due to the industry's extensive and growing use of third parties. ${ }^{93}$ The technical complexities of T\&T implementation make this harder still with high levels of technical expertise required to identify and make sense of industry interference; the industry's SGTIN proposal being a prime example. There is growing evidence that the industry is using third-parties in attempts to gain control of T\&T in a range of countries. In 2012, for example, Codentify was promoted in a T\&T tender through the industry-linked third-party, Fracturecode, ${ }^{11}$ and in 2017, Atos was one of two firms with tobacco industry links which placed a bid for a T\&T tender in Chile. ${ }^{95}$

Most importantly, there is evidence that the tobacco industry has been trying to export text from the TPD into T\&T policy in West Africa. ${ }^{96}$ This supports our findings in indicating that the industry considers EU T\&T legislation to be favourable. It also highlights that other Parties must guard against this possibility. Should such efforts be successful, the tobacco industry may gain control of, and thereby fundamentally undermine, the ITP's envisioned global T\&T system, allowing TTCs to avoid adequate scrutiny and to continue to fail to control their own supply chains. ${ }^{11}$

Policy implications and recommendations

There are steps that the European Commission and EU Member States can take to safeguard EU T\&T against industry interference and to ensure its compliance with the ITP. At the Commission level, the independence criteria for third-parties should be revised so that, at the very least, no company involved with the development and/or implementation of the Codentify technology is eligible.

Member States can require that all authentication elements (eg, holograms, microprints, molecular tags, which are used to establish if a product is genuine or not-see online supplementary appendix 1 for more detail) be sourced independently of the industry. Additional measures to safeguard against collusion between manufacturers and service providers could also be taken (such as Member States having access to contracts between the industry and third-parties relating to EU T\&T).

Other Parties to the ITP should be aware of the EU T\&T system's inconsistencies with the ITP stemming from the TPD's requirements which allow the industry to select data repository providers and auditors, the 'mixed' governance approach adopted by the European Commission, and the insufficient independence criteria which fails to adequately account for the industry's extensive use of third-parties.
What this paper adds

What is already known on this subject

- The Illicit Trade Protocol (ITP) requires countries to implement a track and trace system for tobacco independent of the tobacco industry. Yet the tobacco industry has a vested interest in controlling any tobacco tracking and tracing system in order to avoid scrutiny and minimise its excise payments. The industry's attempts to have its Codentify-based system implemented as a tracking and tracing solution have become increasingly opaque, including using third-parties to create the false impression that the system is independent from industry.

- In December 2017, the European Commission adopted regulations for tracking and tracing in the EU based on the text of the 2014 TPD. On 20 May 2019, tracking and tracing for cigarettes and roll-your-own tobacco was implemented in the EU, based on these regulations.

\section{What this paper adds}

- 17 months after the sale of Codentify to Inexto and PMI's claim that Inexto was independent from the industry, internal documents suggest the industry and Inexto continued to have a financial and operational relationship. They jointly promoted industry tracking and tracing objectives by engaging with EU Member States and proposing technical standards which would have handed tobacco companies further control of the EU's tracking and tracing system.

- This study is the first evaluation of tobacco tracking and tracing operationalisation. It finds that the tobacco industry has succeeded in undermining the independence of the EU's track and trace system. The system delegates key responsibilities to the industry and associated third-parties, raising serious concerns about its compliance with the ITP. The European Commission and Member States should take further steps to protect EU tracking and tracing from industry manipulation and other ITP parties must ensure that their own tracking and tracing systems are fully consistent with the ITP and its values and do not replicate the EU's model.

Contributors All authors conceived the idea for the study. AWAG and ABG developed the research design. AWAG produced first draft and all authors edited.

Funding AWAG \& ABG acknowledge the support of Bloomberg Philanthropies Stopping Tobacco Organizations and Products project funding (www.bloomberg.org)

Disclaimer The opinions expressed are those of the authors' alone.

Competing interests None declared.

Patient consent for publication Not required.

Provenance and peer review Not commissioned; externally peer reviewed.

Data availability statement All data relevant to the study are included in the article or uploaded as supplementary information.

Open access This is an open access article distributed in accordance with the Creative Commons Attribution Non Commercial (CC BY-NC 4.0) license, which permits others to distribute, remix, adapt, build upon this work non-commercially, and license their derivative works on different terms, provided the original work is properly cited, appropriate credit is given, any changes made indicated, and the use is non-commercial. See: http://creativecommons.org/licenses/by-nc/4.0/.

\section{REFERENCES}

1 World Health Organization Conference of the Parties to the WHO Framework Convention on Tobacco Control. Fifth Session. Seoul. 12-17 November 2012. Decision FCTC/CoP 5(1). The Protocol to Eliminate Illicit Trade in Tobacco Products 2012.

2 Joossens L, Raw M. Cigarette smuggling in Europe: who really benefits? Tob Control 1998;7:66-71 
3 Bialous S. Who FCTC, Bialous S. the tobacco industry and the illicit trade in tobacco products, 2014. Available: http://www.who.int/fctc/publications/The-Tobacco-Industryand-the-Illicit-Trade-in-Tobacco-Products.pdf

4 Joossens L, Raw M. How can cigarette smuggling be reduced? BMJ 2000;321:947-50.

5 Nakkash R, Lee K. Smuggling as the "key to a combined market": British American Tobacco in Lebanon. Tob Control 2008; 17:324-31.

6 Gilmore $A B$, Fooks $G$, Drope J, et al. Exposing and addressing tobacco industry conduct in low-income and middle-income countries. The Lancet 2015;385:1029-43.

7 Lee K, Collin J. "Key to the future": British American tobacco and cigarette smuggling in China. Plos Medicine 2006;3:1080-9.

8 The International Consortium of Investigative Journalists. Global reach of tobacco company's involvement in cigarette smuggling exposed in company papers, 2000. Available: https://www.icij.org/investigations/big-tobacco-smuggling/global-reachtobacco-companys-involvement-cigarette-smuggling-exposed-company-papers/ [Accessed 6 Nov 2017].

9 Gilmore $A B$, McKee M. Moving East: how the transnational tobacco industry gained entry to the emerging markets of the former Soviet Union--part I: establishing cigarette imports. Tob Control 2004;13:143-50.

10 Collin J, Legresley E, MacKenzie R, et al. Complicity in contraband: British American tobacco and cigarette smuggling in Asia. Tob Control 2004;13 Suppl 2(suppl_2):ii104-11.

11 Gilmore AB, Gallagher AWA, Rowell A. Tobacco industry's elaborate attempts to control a global track and trace system and fundamentally undermine the illicit trade protocol. Tob Control 2019;28:127-40.

12 Bosely S. Tobacco industry seeking to control anti-smuggling measures, say critics. 14 June, 2018. Available: https://www.theguardian.com/society/2018/jun/14/tobaccoindustry-seeking-to-control-anti-smuggling-measures-say-critics [Accessed 24 Jun 2019].

13 Joossens L, Gilmore AB. The transnational tobacco companies' strategy to promote Codentify, their inadequate tracking and tracing standard. Tob Control 2014;23:e3-6.

14 Ross $H$, Eads M, Yates M. Why governments cannot afford Codentify to support their track and trace solutions. Tob Control 2018:27:706-8.

15 Tobacco Control Research Group. Codentify. TobaccoTactics.org. last modified: 06 SEP 2017. Available: http://www.tobaccotactics.org/index.php?title=Codentify [Accessed 23 Nov 2017].

16 Gilmore AGG, Rowell A. Appendix 1: countries that have used Codentify, 2018. Available: https://tobaccocontrol.bmj.com/content/tobaccocontrol/early/2018/06/ 13/tobaccocontrol-2017-054191/DC1/embed/inline-supplementary-material-1.pdf? download=true [Accessed 2 Apr 2019].

17 Digital Coding \& Tracking Association. ABOUT US. 1 July, 2018. Available: https://web archive.org/web/20180701082608/http://dcta-global.com/about-us.html [Accessed 30 Apr 2019].

18 Tobacco Control Research Group. Digital Coding \& Tracking Association (DCTA). TobaccoTactics.org. last modified: Last modified on 19 July, 2018. Available: https:// tobaccotactics.org/index.php?title=Digital_Coding_\%26_Tracking_Association_ [Accessed 8 May 2019].

19 Teffer P. Cigarette tracking rules risk being DERAILED by lobbyists. 07 Jun, 2017 Available: https://euobserver.com/health/138135 [Accessed 10 Oct 2017].

20 Digital Coding and Tracking Association. Press Release - DCTA technology ownership transferred to Inexto, an affiliate of Impala Group, 2016.

21 Teffer P. Big tobacco suspected of dodging EU anti-smuggling rules, 2016. Available: https://euobserver.com/economic/133899 [Accessed 07 Nov 2017].

22 Crosbie E, Bialous S, Glantz SA. Memoranda of understanding: a tobacco industry strategy to undermine illicit tobacco trade policies. Tob Control 2019:tobaccocontrol-2018-054668.

23 Williams C. Councils urged to reject tobacco industry money, 2014. Available: https:// web.archive.org/web/20140908134955/http://www.ehn-online.com/news/article. aspx?id=12474 [Accessed 11 Mar 2019].

24 Gallagher AWA, Evans-Reeves KA, Hatchard JL, et al. Tobacco industry data on illicit tobacco trade: a systematic review of existing assessments. Tobacco Control 2018.

25 Smith J, Thompson S, Lee K. 'Both sides of the argument'? A critical review of existing evidence on the illicit trade in tobacco products in Canada. Tob Control 2019:tobaccocontrol-2018-054687.

26 Tobacco Control Research Group. PMI IMPACT. TobaccoTactics.org:University of Bath. last modified, 2017. Available: http://www.tobaccotactics.org/index.php?title=PMI_ IMPACT [Accessed 06 Nov 2017].

27 Gallagher A, Evans-Reeves K. Pmi impact: controlling research. controlling policy? 2017. Available: https://medium.com/@ASH_LDN/pmi-impact-controlling-researchcontrolling-policy-9b11562f4dae [Accessed 3 Mar 2019].

28 Tobacco Control Research Group, O'Reilly W. TobaccoTactics.org: University of bath. last modified, 2017. Available: http://tobaccotactics.org/index.php/Will_0\%E2\%80\% 99Reilly [Accessed 7 Nov 2017].

29 European Parliament, Council of the European Union. Directive 2014/40/EU of the European Parliament and of the Council of 3 April 2014 on the approximation of the laws, regulations and administrative provisions of the member states concerning the manufacture, presentation and sale of tobacco and related products and repealing Directive 2001/37/EC 2014
30 European Commission. Commission implementing decision (EU) 2018/576 of 15 December 2017 on tecnical standards for security features applied to tobacco products. Official Journal of the European Union 2018

31 European Commission. Commission implementing regulation (EU) 2018/574 of December 2017 on technical standards for the establishment and operation of a tracability system for tobacco products. Official Journal of the European Union 2018.

32 European Commission. The European system of tobacco traceability and security features operational as of today, 2019. Available: https://ec.europa.eu/health/sites/ health/files/tobacco/docs/20190520_tt_press_en.pdf [Accessed 25 Jun 2019].

33 Teffer P. Cigarette-smuggling expert asks MEPs not to veto new bill, 2018. Available: https://euobserver.com/health/140876 [Accessed 20 Jun 2019].

34 European Commission. Commission Delegated regulation (EU) 2018/573 of 15 December 2017 on key elements of data storage contracts to be concluded as part of a tracability system for tobacco products. Official Journal of the European Union 2018

35 European Commission. EU system of traceability for tobacco products - List of approved providers of primary repositories, 2018. Available: https://ec.europa.eu/ health/sites/health/files/tobacco/docs/primaryrepositories_approvedproviders en.pdf [Accessed 20 Feb 2019].

36 European Commission. Public feedback on the draft secondary legislation relating to systems of traceability and security features for tobacco products, as provided for under articles 15 and 16 of Directive 2014/40/EU, 2017. Available: https://ec.europa. eu/health/tobacco/2017_publicfeedback_products_en [Accessed 25 Sep 2017].

37 European Commission. Commission staff working document: impact assessment, 2017. Available: https://ec.europa.eu/health/sites/health/files/tobacco/docs/tt_ia_en. pdf [Accessed 20 Feb 2019].

38 European Commission. Inception impact assessment, 2016. Available: http://ec europa.eu/smart-regulation/roadmaps/docs/2015_sante_694_695_696_ia_da_tpd_ en.pdf [Accessed 20 Feb 2019].

39 European Commission. Tobacco track and trace systems: questions and answers, 2017. Available: http://europa.eu/rapid/press-release_MEM0-17-5270_en.pdf [Accessed 20 Feb 2019].

40 Everis. Implementation analysis regarding the technical specifications and other key elements for a future EU system for traceability and security features in the field of tobacco products, 2018. Available: https://ec.europa.eu/health/sites/health/files/ tobacco/docs/2018_technicalspecifications_analysis_en.pdf [Accessed 13 Mar 2019].

41 Eurogroup Consulting, sovereign Border Solutions. Analysis and feasibility assessment regarding EU systems for tracking and tracing of tobacco products and for security features, 2015. Available: https://ec.europa.eu/health//sites/health/files/tobacco/docs/ 2015 tpd tracking tracing frep en.pdf [Accessed 5 Mar 2019].

42 European Commission. Revision of the tobacco products Directive 2014/40/EU, 2014. Available: https://ec.europa.eu/health/tobacco/products/revision en [Accessed $25 \mathrm{Sep}$ 2017].

43 Michalopoulos S. Commission hits back at criticism over tobacco track and trace proposal, 2017. Available: https://web.archive.org/web/20180223012744/https:// www.euractiv.com/section/economy-jobs/news/commission-hits-back-at-criticismover-tobacco-track-and-trace-proposal/ [Accessed 12 Mar 2019].

44 Stevens C. The \#Tobacco directive: how the European Commission sidelined the European Parliament, 2019. Available: https://web.archive.org/web/ 20180216234543/https://www.eureporter.co/health/2018/02/16/the-tobaccodirective-how-the-european-commission-side-lined-the-european-parliament/ [Accessed 11 Mar 2019].

45 Stevens C. The EU cracks down on \#Tobacco, but does it go far enough? 2019. Available: https://web.archive.org/web/20190313160733/https://www.eureporter. co/health/2019/01/15/the-eu-cracks-down-on-tobacco-but-does-it-go-far-enough/ [Accessed 13 Mar 2019].

46 Stevens C. \#EP Debate: We need to put the reins on Big Tobacco, 2019. Available: https://web.archive.org/web/20190212180412/https://www.eureporter.co/health/ 2019/02/01/ep-debate-we-need-to-put-the-reins-on-big-tobacco/ [Accessed 11 Mar 2019].

47 International Tax Stamp Association. The relationship between international law and legislative, delegated \& implementing acts of the European Union, 2018. Available: https://www.tax-stamps.org/news-article/the-relationship-between-international-lawand-legislative-delegated-implementing-acts-of-the-european-union [Accessed $29 \mathrm{Ap}$ 2019].

48 Operational Management Committee + Inexto. Conference call 7 November, 2017: Agenda \& Notes 7 November, 2017

49 Operational Management Committee + Inexto. Conference call 2 October, 2017 : Agenda \& Notes 2 October, 2017

50 Forster N. The Analysis of Company Documentation. In: Cassell C, Symon G, eds. Qualitative methods in organizational research a practical guide. London: Sage, 1994: 147-66.

51 European Commission. Targeted stakeholder consultation on the implementation of an EU system for traceability and security features pursuant to articles 15 and 16 of the tobacco products Directive 2014/40/EU, 2015. Available: https://ec.europa. eu/health/sites/health/files/tobacco/docs/2015 tpd_co57_en.pdf [Accessed 22 Jan 2018]

52 Evans-Reeves KA, Hatchard JL, Gilmore AB. 'It will harm business and increase illicit trade': an evaluation of the relevance, quality and transparency of evidence submitted 
by transnational tobacco companies to the UK consultation on standardised packaging 2012. Tob Control 2015;24:e168-77.

53 World Health Organization. Protocol to eliminate illicit trade in tobacco products, 2013. Available: http://www.who.int/fctc/protocol/illicit_trade/protocol-publication/ en/ [Accessed 21 Jan 2018]

54 Tobacco Control Research Group. Front Groups. Last modified, 2012. Available: http:// www.tobaccotactics.org/index.php/Lobbying_Decision_Makers [Accessed 21 Jan 2015].

55 Impala. Impala - Arjo Solutions \& Inexto, 2016. Available: http://www.impala-sas.com/ en/participations/arjo-solutions-inexto [Accessed 29 Sep 2017].

56 Imperial brands. Logista. undated. Available: https://web.archive.org/web/ 20181231141417/http://www.imperialbrandsplc.com/About-us/Our-companies/ Logista.html [Accessed 31 Dec 2018].

57 Bundesdruckerei GmbH. Track \& Trace and Security Features Pilot Project by Bundesdruckererei GmbH, 2016. Available: https://docplayer.net/48579155-Track-tt-trace-and-security-feature-pilot-status-project-pilot-by-bdr-bundesdruckerei-gmbh. html [Accessed 30 Apr 2019].

58 European Commission. Application of ISO/IEC 15459 to the system of tobacco traceability, meeting of the group of experts on tobacco policy, power point presentation. Brussels: European Commission, 2017.

59 Joossens L. Traceability: the tobacco industry is part of the problem, not the solution. Tob Control 2019:28:121-2.

60 GS1 Norway. Guideline for unique identification of products with SGTIN (serialized GTIN). labelling with GS1 Datamatrix barcode and tagging with EPC / RFID gen 2 UHF RFID tags, 2018. Available: https://www.gs1.org/docs/technical_industries/ Construction/GS1\%20Guideline \%20unique \%20ID\%20for\%20products $\% 20$ in $\%$ 20Construction\%20v1.1\%20-\%202018.pdf [Accessed 7 May 2019].

61 KPMG. Illicit cigarette trade in the Maghreb region, 2017. Available: https://home. kpmg.com/uk/en/home/insights/2017/07/illicit-cigarette-trade-in-the-maghreb-region. html [Accessed 20 Dec 2017].

62 KPMG. Illicit tobacco in Australia 2016, 2017. Available: https://home.kpmg.com/uk/ en/home/insights/2017/04/illicit-tobacco-in-australia-2016.html [Accessed 20 Dec 2017].

63 KPMG. Project StAR 2010 results 2011

64 Tobacco Control Research Group. KPMG. TobaccoTactics.org: University of bath. last modified, 2017. Available: http://www.tobaccotactics.org/index.php?title=KPMG [Accessed 06 Nov 2017].

65 KPMG, GS1. Track and trace approaches in tobacco. KPMG. KPMG, 2014.

66 British American Tobacco. British American tobacco: targeted stakeholder consultation on the implementation of an EU system for traceability and security features pursuan to articles 15 and 16 of the tobacco products Directive 2014/40/EU, 2015. Available: https://ec.europa.eu/health/sites/health/files/tobacco/docs/2015_tpd_co68_en.pdf [Accessed 8 May 2019].

67 Philip Morris International. Philip Morris international: targeted stakeholder consultation on the implementation of an EU system for traceability and security features pursuant to articles 15 and 16 of the tobacco products Directive 2014/40/ EU, 2015. Available: https://ec.europa.eu/health/sites/health/files/tobacco/docs/2015 tpd_co62_en.pdf [Accessed 8 May 2019].

68 Imperial Tobacco. Imperial tobacco limited: targeted stakeholder consultation on the implementation of an EU system for traceability and security features pursuant to articles 15 and 16 of the tobacco products Directive 2014/40/EU, 2015. Available: https://ec.europa.eu/health/sites/health/files/tobacco/docs/2015_tpd_co66_en.pdf [Accessed 8 May 2019].

69 Japan Tobacco International. Japan tobacco international: targeted stakeholder consultation on the implementation of an EU system for traceability and security features pursuant to articles 15 and 16 of the tobacco products Directive 2014/40/ EU, 2015. Available: https://ec.europa.eu/health/sites/health/files/tobacco/docs/2015 tpd_c084_en.pdf [Accessed 8 May 2019].

70 Digital Coding \& Tracking Association. Digital Coding \& Tracking Association: Targeted stakeholder consultation on the implementation of an EU system for traceability and security features pursuant to Articles 15 and 16 of the Tobacco Products Directive 2014/40/EU, 2015. Available: https:/lec.europa.eu/health/sites/health/files/tobacco/ docs/2015_tpd_c057_en.pdf [Accessed 8 May 2019].

71 European Commission Directorae-General for Health and Food Safety. Meeting of the group of experts on tobacco policy. final summary record. meeting date: 08 November 2017, 09.30 - 17:0. 8 November 2017. Available: https:/ec.europa.eu/health/sites/ health/files/tobacco/docs/ev_20171108_sr_en.pdf [Accessed 8 May 2019].

72 Tobacco Control Research Group. Coalition against illicit trade (CaiT). last modified on, 2018. Available: http://tobaccotactics.org/index.php?title=Coalition_Against_ Illicit Trade [Accessed 20 Feb 2019].

73 sbv Improver. Verification of systems biology research in the age of collaborative competition, 2014. Available: https://web.archive.org/web/20190303203553/https:// www.pmiscience.com/resources/docs/default-source/library-documents/poster e bilal_biopharma.pdf?sfvrsn=1840f606_2 [Accessed 3 Mar 2019].

74 Bostic C. Philip Morris \& IBM IMPROVER project: downplaying links between smoking \& disease, 2013. Available: https://blogs.bmj.com/tc/2013/05/13/philip-morris-ibmimprover-project-downplaying-links-between-smoking-disease/ [Accessed $3 \mathrm{Mar}$ 2019].

75 sbvimprover. FAQs. undated. Available: https://web.archive.org/save/https://www. sbvimprover.com/faqs [Accessed 5 Mar 2019].

76 Tobacco Control Research Group. List of successful PMI impact applicants. TobaccoTactics.org. last modified: last modied, 2019. Available: http://www. tobaccotactics.org/index.php?title=List_of_Successful_PMI_IMPACT_Applicants [Accessed 27 Mar 2019].

77 IBM Global Business Services. Clear: an analytical subscription from IBM, 2012. Available: https://web.archive.org/web/20131017051721/https://www-935.ibm.com/ services/multimedia/CPS03023-USEN-00.pdf [Accessed 3 Mar 2019].

78 Philip Morris. DENTSU Japan visitors, 1995. Available: https://www.industrydocument slibrary.ucsf.edu/docs/\#id=xtjf0036 [Accessed 3 Mar 2019].

79 Balgley A. Balgley, Annemarie, 2001. Available: https://www.industrydocument slibrary.ucsf.edu/tobacco/docs/\#id=hjgf0036 [Accessed 3 Mar 2019].

80 blue-infinity. blue-infinity joins Dentsu Aegis network, 2017. Available: https://web. archive.org/web/20190303205451/https://www.blue-infinity.com/blog/2017/01/13/ blue-infinity-joins-dentsu-aegis-network [Accessed 3 Mar 2019].

81 dentsu AEGIS network. blue-infinity linked by ISOBAR. undated. Available: https:// web.archive.org/web/20190318151100/https://dentsu.dentsuaegistracking.com/ unsere-brands/blue-infinity/ [Accessed 18 Mar 2019].

82 Videojet. Videojet and blue-infinity traceability workshop supports TPD II regulation readiness, 2015. Available: https://web.archive.org/web/20180412040851/https:// www.videojet.com/us/homepage/general/news/videojet-and-blue-infinity-traceabilityworkshop.html [Accessed 3 Mar 2019].

83 blue-infinity. our work. undated. Available: https://web.archive.org/web/ 20190318153501/https://www.blue-infinity.com/our-work?page=2 [Accessed 18 Mar 2019].

84 blue-infinity. our work (2). undated. Available: https://www.blue-infinity.com/ourwork/blue-infinity-shopmachine [Accessed 18 Mar 2019].

85 Videojet. tobacco. undated, 2019. Available: https://web.archive.org/web/ 20181012074701/https://www.videojet.com/us/homepage/industry-solutions/ tobacco.html [Accessed 13 Mar 2019].

86 asfixiando el Contrabando. El nuevo disfraz de la industria del tabaco para enganar a la ue, 2018. Available: https://web.archive.org/web/20190430161950/http://asfixian doelcontrabando.info/el-nuevo-disfraz-de-la-industria-del-tabaco-para-enganar-a-laue/ [Accessed 30 Apr 2019].

87 Movilitas. Movilitas USPs track trace 2.0. 16 March, 2016. Available: https://web. archive.org/web/20190430170835/https://www.slideshare.net/PatrickBuckner/ movilitas-usps-track-trace-20?from_action=save [Accessed 30 Apr 2019].

88 Honeywell Movilizer. Partner overview: selection of Movilizer partners. undated. Available: https://web.archive.org/web/20190403122103/https://movilizer.com/ourpartners.html [Accessed 3 Apr 2019].

89 Movilizer. our projects, 2016. Available: https://web.archive.org/web/ 20161023055935/https://movicoders.com/our-projects/ [Accessed 3 Mar 2019].

90 nzier. Review of ernst \& Young's Report on New Zealand's Illicit Tobacco Market, 2010. Available: https://www.parliament.nz/resource/0000113924 [Accessed 07 Nov 2017].

91 Tobacco Control Research Group. Deloitte. TobaccoTactics.org. last modified: last modified 10 January, 2017. Available: https://www.tobaccotactics.org/index.php? title=Deloitte [Accessed 1 Jun 2019].

92 PriceWaterhouseCoopers. Australia's illegal tobacco market - counting the cost of Australia's black market, 2010. Available: http://www.tobaccotactics.org/images/0/ 09/100201_-_Price_Waterhouse_Cooper\%27s_-_pwc_report.pdf [Accessed 06 Nov 2017].

93 Peeters S, Costa H, Stuckler D, et al. The revision of the 2014 European tobacco products directive: an analysis of the tobacco industry's attempts to 'break the health silo'. Tob Control 2016;25:108-17.

94 Costa H, Gilmore AB, Peeters $\mathrm{S}$, et al. Quantifying the influence of the tobacco industry on EU governance: automated content analysis of the EU tobacco products Directive. Tob Control 2014:23:473-8.

95 World Bank Group. Confronting illicit tobacco trade: a global review of country experiences, 2019. Available: http://documents.worldbank.org/curated/en/ 677451548260528135/pdf/133959-REPL-PUBLIC-6-2-2019-19-59-24-WBGTobac colllicitTradeFINALvweb.pdf [Accessed 28 May 2019].

96 Personal correspondence, 10/02/2019 